\title{
A study of commuters' transport modes choices and transport policy intentions
}

\author{
Y.-C. Lin \\ School of Architecture, Planning and Landscape, \\ University of Newcastle upon Tyne, UK
}

\begin{abstract}
Taiwan is a developing country, with a population of around 23 and a half million. The country's recent increase in wealth has resulted, amongst other things, in more people aspiring to the lure of car ownership. In Taiwan in 2013, the average person owned 1.09 cars, and the average person owned 1.65 motorcycles. Since 2010, as part of their urban development to attract users to travel by public transport systems rather than by car, transport planners in Taipei have been implementing the MRT Tricyclic three-line construction, and the MRT Pilot Bus. The MRT Tricyclic three-line construction aims to encourage the public to travel by public transport, thereby decreasing the use of private transport in Taipei City and New Taipei City. The intention is to strengthen the role of New Taipei City within the Taipei metropolitan area, making it the most important investment in public transport within the next ten years. In 2010, the government designed MRT networks with New Taipei city at their centre, emphasizing the networks' primary importance for New Taipei city. The unexpectedly high take-up of the MRT Pilot Bus services provided while the MRT Tricyclic three-line was under construction, showed the MRT Pilot Bus service provision to be an effective policy in persuading private transport users to switch from using private vehicles to using public transport. The paper concluded that transport policies and initiatives aimed at influencing people away from using motorized vehicle modes towards using more sustainable modes, should take a holistic approach, with two-way communication between the public and the government.

Keywords: commuting, public transport, transport modes choices, transport policy, car use.
\end{abstract}




\section{Introduction}

In the past two decades, many cities have experienced rapid population increases and economic growth. Approximately 3 billion people - more than half of the world's population - now live in urban areas (Cohen [1]). In the last ten years, economists have pointed out that the continuing increase in the share of the population who live in cities, and are therefore regarded as urbanized, is a positive achievement on the path toward wealth and prosperity (Bloom et al. [2]). Based on such a view, urbanization can enhance economic growth, thereby increasing the long term wealth of nations. Consequently, there is a strong correlation between urbanization and economic development: higher-income countries tend to be more urbanized than lower-income countries, though urbanization in lower-income countries rises at a quicker rate with economic growth than it does in higher-income countries (Roberts and Kanaley [3]). One manifestation of this increased wealth is the expansion, throughout the world, of car ownership, much of which is in the developed world (Button et al. [4]). It is possible, therefore, that urbanized cities in lower-income countries may also witness increased aspiration to car ownership and to travelling by car in general. For many people, the car is a status symbol, expressed by the model of car (Steg [5]).

However, with car use comes environmental problems, such as air pollution and noise pollution. Many countries have expressed a significant concern about the personal transportation emissions (Lorna [6]). According to the Key World Energy Statistics (IEA [7]), in 2009 the $\mathrm{CO}_{2}$ released from Taiwan was 250.11 Mt, constituting $0.86 \%$ of worldwide $\mathrm{CO}_{2}$ emissions, placing Taiwan as $23^{\text {rd }}$ in the world ranking. In terms of the average individual's personal $\mathrm{CO}_{2}$ emission, Taiwan ranked $17^{\text {th }}$, with 10.89 tons per person. Among all Asian countries, Taiwan was the biggest culprit, contributing an amount somewhere between that contributed by Estonia and the Russian Federation (a figure higher than Korea, OECD, Japan and the United Kingdom). Thus, in order to address the environmental problems emanating from car use, the governments of many countries have implemented a series of policy measures; for example: different informational measures, subsidies for alternative modes of travel, subsidies for more environmentally-friendly technology, restrictions on car use, and land management tools to attract people to travel by public transport and to reduce the use of private transport [8-11]. These policy measures play an important role in changing travel behaviour, with the aim of decreasing the attractiveness of car use, as well as impacting on changing travel behaviour for different target groups [12]. This paper therefore develops a critical evaluation of transport policy in Taiwan, aiming to increase public transport usage and to assess the potential for influencing the public's mode of transport choice through better policy matching to the needs of people's journeys to and from work. 


\section{Methodology}

In general, the role of mixed method research is not only in validating qualitative research and quantitative research, but also in utilizing the strength of the two methods for minimizing their individual weaknesses. Using mixed methods therefore minimizes the limitations that these two individual methods, both have $[13,14]$. The mixed-method approach predominantly adopted in the study included: quantitative questionnaires and qualitative semi-structured interviews.

\subsection{Questionnaire development}

The survey was designed to obtain data on commuters' choices of mode of transport and their thoughts on transport policies/facilities; these two approaches were illustrated in the data collection. The survey allowed flexibility in terms of the order in which the topics were considered and perhaps more significantly, it ensured an appropriate number of respondents with a suitable balance of age bands guaranteed. Not only that, but by conducting the interviews, it would be clear from the face-to-face context if false information was being given; this would be less feasible with telephone surveys, and not possible with questionnaires (Denscombe [15]). In addition to this, the findings of the survey were applied to design the interview questions, which were then employed in qualitative data for policy-makers in order to obtain data from their points of view in terms of transport policy, as well as the implications of transport policy. This is one possible way of understanding policy-makers' transport policy implications and their points of view in terms of the findings of commuters' survey.

\subsubsection{Sample population}

Zhonghe District, in New Taipei City (a satellite town of Taipei City, see figure 1 ), was chosen as the case study area. It is located in the south-west of New Taipei City, and its total population is 414,939 , with 157,474 households, and the total area is $20.294 \mathrm{Km}^{2}$ [16]. In terms of the geological location of the Zhonghe District in New Taipei City, it is located in the west of Yonghe District, north of Xindian District, and the east of Banqiao District. In the north-east around Zhonghe District, is Xindian River, which demarcates the boundary between Taipei City and New Taipei City. Hua Chung Bridge connects Zhonghe District to Taipei City.

Zhonghe District is a transport hub, easily accessible to other districts of New Taipei City and Taipei City. The research thus focuses on investigating the empirical evidence of individuals who live in a typical and representative community: the He Ping Shin Jiun in Xiufeng village, within Zhonghe District in New Taipei City, Taiwan.

\subsubsection{Statistical analysis}

An extensive community survey of 750 males and 750 females in He Ping Shin Jiun (in Zhonghe District), was conducted in January, 2013. 500 questionnaires were then delivered, which were face-to-face surveys, with 169 being returned 


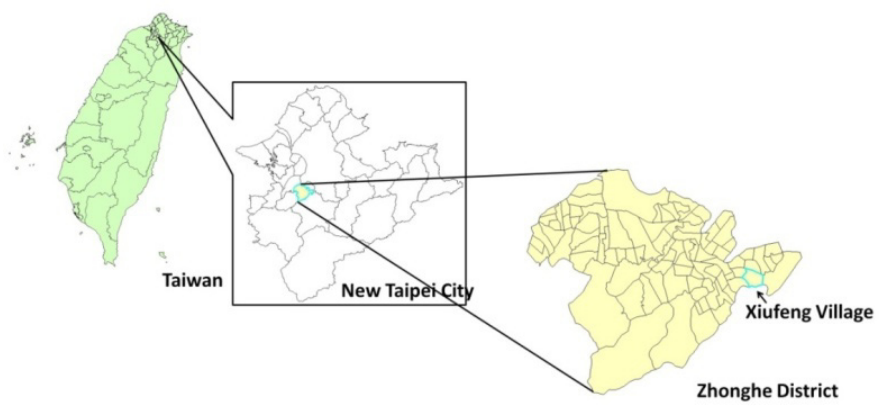

Figure 1: The scope of Zhonghe District.

(33.8\%). The commuters who were targeted in the survey all lived in He Ping Shin Jiun; the survey was designed to collect information from the following two study groups:

- Commuters i.e. both males and females 18 years old and above and in fulltime work;

- $\quad$ Drivers of private vehicles (including motorcycles and cars);

- Commuters who travel to work by the metro or bus.

An evaluation tool was developed using a series of inter-linked spreadsheets and databases, and the survey output was carried out using the Statistical Package SPSS Statistics.

\subsection{Semi-structured interviews}

Qualitative data were mainly obtained through policy-makers' interviews, and governmental publications. The semi-structured interviews were conducted to six targeted interviewees, who worked in related transport departments (see Table 1). The analyses were carried out from the grouping response of the policy-makers, and the commuters' survey.

\section{Analysis of results}

\subsection{Commuters choose to use private transport}

An analysis of the collected information has shown that four modes of transport are primarily used by residents of the He Ping Shin Jiun community for their work journeys: cars, motorcycles, metro and bus. It is evident that there are variations in the different modes of transport usage patterns, depending on the users' socio-economic status (income, educational levels, and occupation), demographic characteristics (gender and age), and the attributes of the modes of transport. 169 of the 500 questionnaires delivered were returned $(33.8 \%)$, of which: 36 respondents use cars, 58 use motorcycles, 43 use buses, and 32 use 
Table 1: The list of interviewed policy-makers.

\begin{tabular}{|l|l|l|l|l|}
\hline No. & $\begin{array}{l}\text { Interview } \\
\text { respondents }\end{array}$ & $\begin{array}{l}\text { Position } \\
\text { held }\end{array}$ & Organization & Code \\
\hline 1 & Government & The Chief & $\begin{array}{l}\text { Transportation Department, } \\
\text { New Taipei City Government }\end{array}$ & G01 \\
\hline 2 & Government & $\begin{array}{l}\text { The Vice } \\
\text { Chief }\end{array}$ & $\begin{array}{l}\text { Urban and Rural Development } \\
\text { Department, New Taipei City } \\
\text { Government(?) }\end{array}$ & G02 \\
\hline 3 & Government & $\begin{array}{l}\text { Section } \\
\text { Manager }\end{array}$ & $\begin{array}{l}\text { Comprehensive Planning } \\
\text { Section, Transportation } \\
\text { Department, New Taipei City } \\
\text { Government }\end{array}$ & G03 \\
\hline 4 & Government & $\begin{array}{l}\text { Team } \\
\text { Leader }\end{array}$ & $\begin{array}{l}\text { Institute of Transportation, the } \\
\text { Ministry of Transportation and } \\
\text { Communications (MOTC) }\end{array}$ & G04 \\
\hline 5 & Government & $\begin{array}{l}\text { Section } \\
\text { Manager }\end{array}$ & $\begin{array}{l}\text { Transportation Management } \\
\text { Section, Transportation } \\
\text { Department, New Taipei City } \\
\text { Government }\end{array}$ & G05 \\
\hline 6 & Government & $\begin{array}{l}\text { Vice Chief } \\
\text { Engineer }\end{array}$ & $\begin{array}{l}\text { Department of Rapid Transit } \\
\text { Systems, New Taipei City } \\
\text { Government }\end{array}$ & G06 \\
\hline
\end{tabular}

the metro., The usage of private transport $(55.62 \%)$ is greater than that of public transport $(44.38 \%)$. The determinant mode of transport travel to work by respondents $(34.32 \%$ of the sample) is motorcycle. The lower purchase, upkeep and maintenance costs of motorcycles play a significant role in that. For example, each 125c.c.motorcycle costs around NTD 50,000 60,000, which is affordable for many more people than cars. The other modal shares of interest for the whole sample, are $25.44 \%$ for bus users, $21.30 \%$ for car drivers, and $18.94 \%$ for metro users. The statistics of the modes of transport within the survey are shown in Table 2.

Table 2: $\quad$ The travel statistics of the He Ping Shin Jiun survey.

\begin{tabular}{|l|c|c|}
\hline & Number returned & Percentage response rate \\
\hline Travel by car & 36 & $21.30 \%$ \\
\hline Travel by motorcycle & 58 & $34.32 \%$ \\
\hline Travel by metro & 32 & $18.94 \%$ \\
\hline Travel by bus & 43 & $25.44 \%$ \\
\hline Total & 169 & $100.0 \%$ \\
\hline
\end{tabular}

It can be seen from Table 3 that the most significant reason both for car drivers and motorcyclists using private transport to travel to work is "Car/motorcycle is convenient to get to the work place". $29.3 \%$ of car drivers 
think that the "car is convenient to get to the work place", followed by $27.3 \%$ who think that the "car is needed before or after work". Also, $18.2 \%$ think that the "car is used without time limited", and $17.2 \%$ think that the "car is needed to drop off/pick up others". For motorcyclists, $36.4 \%$ of them think that the "motorcycle is convenient to get to the work place" and $25.0 \%$ think that the "motorcycle is needed before or after work". 24.2\% think that the "motorcycle is used without time limited", and $12.1 \%$ think that the "motorcycle is needed to drop off/pick up others".

Table 3: The reasons for car drivers/ motorcyclists choose car/motorcycle to get to work.

\begin{tabular}{|l|c|c|}
\hline & Car drivers & Motorcyclists \\
\hline $\begin{array}{l}\text { Car/motorcycle is convenient to get to the work } \\
\text { place }\end{array}$ & $29.3 \%$ & $36.4 \%$ \\
\hline Car/motorcycle is needed before or after work & $27.3 \%$ & $25.0 \%$ \\
\hline $\begin{array}{l}\text { Car/motorcycle is needed to drop off/pick up } \\
\text { others }\end{array}$ & $17.2 \%$ & $12.1 \%$ \\
\hline Car/motorcycle is used without time limited & $18.2 \%$ & $24.2 \%$ \\
\hline Other & $8.1 \%$ & $2.3 \%$ \\
\hline Total & $100.0 \%$ & $100.0 \%$ \\
\hline
\end{tabular}

\subsection{Commuters' opinion regarding climate change}

It can be seen from Table 4 that $66.7 \%$ of car users think that climate change is caused by both of human activities and natural occurrence, $13.9 \%$ of car drivers think that climate change is purely a natural occurrence, $11.1 \%$ of car drivers do not believe that climate change has happened, and only $8.3 \%$ of car drivers think that climate change is caused purely by human activities. Regarding motorcyclists' opinions, $60.3 \%$ think that climate change is caused by both human activities and natural occurrence, $24.1 \%$ of motorcyclists think it is caused by purely human activities. $13.8 \%$ it is purely a natural occurrence, and $1.7 \%$ do not believe that climate change has happened. Public transport users' opinions regarding climate change demonstrated that $78.1 \%$ of metro users think climate change is caused by both human activities and natural occurrence.9.4\% think that climate change is caused purely by human activities, $6.3 \%$ think that climate change is purely a natural occurrence, whilst the same amount $(6.3 \%)$ do not believe climate change has happened. For bus users' opinions on climate change, $74.4 \%$ think climate change is caused by both human activities and natural occurrence, $16.3 \%$ of bus users think that climate change is caused purely by human activities. $7 \%$ think climate change is purely a natural occurrence, and $2.3 \%$ do not believe that climate change has happened. 
Table 4: Commuters' opinion regarding climate change.

\begin{tabular}{|l|c|c|}
\hline & Car drivers & Motorcyclists \\
\hline $\begin{array}{l}\text { Climate change is caused purely by human } \\
\text { activities. }\end{array}$ & $8.3 \%$ & $24.1 \%$ \\
\hline Climate change is purely a natural occurrence. & $13.9 \%$ & $13.8 \%$ \\
\hline $\begin{array}{l}\text { I think climate change is caused by both of } \\
\text { them. }\end{array}$ & $66.7 \%$ & $60.3 \%$ \\
\hline $\begin{array}{l}\text { I do not believe that climate change has } \\
\text { happened }\end{array}$ & $11.1 \%$ & $1.7 \%$ \\
\hline Total & $100.0 \%$ & $100.0 \%$ \\
\hline
\end{tabular}

\subsection{Commuters' priority on the policies and facilities of buses}

The findings of the survey point out that car drivers think the option of "To increase the frequency of bus" has the highest percentage $(44.44 \%)$, thereby representing the highest priority among all of the policies on buses (see Table 5). As car users stated that their reason for not wanting to take the bus was dislike of time wasted waiting for the bus to arrive, if buses ran with greater frequency, these car users would be more likely to commute by bus. "All bus will improve into the low chassis bus" was the second highest choice, with $16.67 \%$. The last priority, which accounted for $2.78 \%$, for car users was "The discount of travelling one way for bus-to-bus transfer", which is the third highest percentage. For motorcyclists, $55.2 \%$ gave the highest priority as "The discount of travelling one way for bus-to-bus transfer", followed by $29.3 \%$ of motorcyclists, who think chose as their second highest priority "To increase the frequency of bus". The remaining $15.5 \%$ of motorcyclists think that "All buses will be improved into the low chassis bus" is the third priority among all the factors.

Table 5: Commuters' priority on the policies and facilities of the buses.

\begin{tabular}{|l|c|c|}
\hline Transport policies & Car drivers & Motorcyclists \\
\hline $\begin{array}{l}\text { All bus will be improved into the low } \\
\text { chassis bus }\end{array}$ & $16.67 \%$ & $15.5 \%$ \\
\hline $\begin{array}{l}\text { The discount of travelling one way for } \\
\text { bus-to-bus transfer }\end{array}$ & $2.78 \%$ & $55.2 \%$ \\
\hline To increase the frequency of bus & $44.44 \%$ & $29.3 \%$ \\
\hline Missing System & $36.11 \%$ & - \\
\hline Total & $100.0 \%$ & $100.0 \%$ \\
\hline
\end{tabular}




\section{Discussion}

\subsection{MRT Tricyclic three-line construction: encouraging public transport usage}

Transport planners mainly use a modal shift approach to reduce levels of car use, making public transport systems more attractive. As a result, they implemented a measure of MRT Tricyclic three-line construction, which integrated an MRT pilot bus measure. MRT Tricyclic three-line construction is not only the main direction of the transport policy in New Taipei City, but it is also the most important investment of public transport system within the last ten years. Transport planners took three aspects into account for implementing MRT Tricyclic three-line construction: transport aspects, economic development aspects, and environmental aspects [11]. Regarding the transport aspect, the networks of the MRT Tricyclic three-line construction will benefit more than 6 million citizens who live in Taipei City and New Taipei City, saving travel time. For example, the public travel from Furen University to Taipei Main Station usually takes around 40 to 50 minutes, but after the MRT Xinzhuang line was opened in 2012, travel time was shortened to 26 minutes: a reduction of more than half. In terms of economic development, the MRT lines of the MRT Tricyclic three-line construction were designed to connect with the existing MRT lines in Taipei City in order to emphasize the importance of New Taipei City and boost its development in the Taipei metropolitan area. The MRT Tricyclic three-line construction has become indispensable in serving the residents of Taipei City and New Taipei City. In addition, in the local area spatial, socio-economic, and industrial development investments will be increased in Taipei City, New Taipei City and Taoyuan City; travel time and costs will be dramatically reduced. For the environment, the MRT is a low carbon emission railway transport system, which saves energy with. The construction models of the MRT are either underground construction or elevated construction, alleviating the likelihood of both traffic jams and car accidents.

In this sense, the transport, the economy and the environment all benefit from an MRT Tricyclic three-line construction It not only shortens travel time for the locals, and emphasizes the importance of New Taipei City, but it also boosts spatial, socio-economic, and industrial development in the Taipei metropolitan area. Also, the MRT Tricyclic three-line construction contributes to fewer environmental problems than cars/ motorcycles. However, there is an issue that should be considered: whether the New Taipei City government has enough funding to implement the MRT Tricyclic three-line construction, which will come in at a cost of around $£ 2$ million: a heavy burden for both of the local, and central governments.

\subsection{MRT pilot bus}

The MRT pilot bus is the policy measure to familiarize private transport users with travelling by bus during MRT Tricyclics three-line construction phase. This 
policy measure aims at pushing the public's travel behaviour towards using buses, and reducing cars/motorcycles prior to the completion of construction on the MRT Tricyclic three-line construction. This is a way to attract private transport users to using buses during the period in which the MRT Tricyclic three-line is being constructed, and to generate the habit of using it for travelling to and from work. In 2014, there were 4 MRT Pilot Bus lines, 28 Rapid Bus lines, 183 city bus lines, 167 new bus lines, 159 associated bus lines, and 16 Road passenger transport lines all serving the citizens of New Taipei City, capturing almost570,000 passengers per day. Among those buses are 729 low chassis buses, only 2 electric buses, and 37 hybrid electric plus low chassis buses. Interviewees, G01 and G05 both explain:

"There are more than 1000 city buses and more than 600 low chassis buses in New Taipei City. They are expected to replace half of the current fleet by the end of 2014. In the past three years, the city buses expanded from 1100 to 2000 in New Taipei City, with increasing numbers but an unchanged proportion. Now, we are trying our best to replace low chassis buses, allowing people to get on and off easily. [...]."(G01).

"The low chassis bus is the target of transport policies. Now 35\% of buses are low chassis buses in New Taipei City. Due to the shapes of the roads, and some mountain roads, some areas are not suitable for running low chassis buses. The target is to reach 50\% of low chasis buses before the end of 2014. [...]." (G05).

The government has two main reasons for using a low-chassis bus in New Taipei City: firstly, low-chassis buses are environmentally friendly, contributing lower exhaust emissions than traditional petrol or diesel-driven buses. Secondly, getting on and off buses, in particular for elderly, disabled people and children, is easy, convenient, and accessible. The majority of interviewees indicated that electric, hybrid electric, and low chassis buses expend lower $\mathrm{CO} 2$ emissions than traditional buses. Interviewees $\mathrm{G} 02$ and G06, both from New Taipei City Government, supported the idea that those modes of buses fit in the concepts of green transport in the following state:

"[...].The buses will gradually change into low-polluting buses (including non-polluting electric buses), double low chassis buses. Also, the whole bus information platforms, integrate public transport information, and provide seamless services of public transport and enhance the services of disadvantaged minorities." (G02).

"New Taipei City is the first city to use electric buses, and Transportation Department of New Taipei City currently subsidizes low chassis buses and hybrid electric low chassis buses. With the MRT being a green form of public transport, the Transportation Department of New Taipei City hopes the MRT pilot buses will also match the concepts of green public 
Transportation Department of New Taipei City. [...].the MRT Pilot buses are low chassis buses, so just as with the flat MRT carriages and platforms, the elderly can conveniently get on these buses. In addition, hybrid electric low chassis buses are environmentally friendly, thus matching the concept of MRT green transport, so the transportation subsidization is mainly for low chassis buses and hybrid electric plus low chassis buses." (G06).

Every year, the New Taipei City government provides $£ 20,000,000$ funding to the bus companies to upgrade their traditional buses to low chassis models. The funding for these buses is around $£ 18,000$ to $£ 20,000$ each, with an electric bus around $£ 180,000$. Nevertheless, hybrid electric low chassis buses and electric buses will not be the main modes of buses for bus the companies, due to the purchase, running and maintenance being so much more expensive than low chassis buses. Aside from this, the technology of hybrid electric low chassis buses and electric buses are not advanced in Taiwan, and the 'life expectancy' and charging performance of them are not yet stable enough. The interviewee, G03 explained:

"The government has NT\$100 million in funds to upgrade low chassis buses and hybrid electric low chassis buses every year. Bus Companies apply for these annual subsidies, but there are more low chassis buses than hybrid electric low chassis buses. [...]. In addition, the costs of maintenance for hybrid electric low chassis buses is high. The technology of electric buses has not yet reached an advanced enough stage, as a result, they have not been fully implemented."(G03).

It is apparent that New Taipei City government's current direction on the transport policy measure of buses has not yet met travelers' expectations. The government regards low chassis buses as the most popular mode of bus to replace traditional buses, because of its more favourable costs, performance and accessibility compared to hybrid electric low chassis buses and electric buses. However, users of different modes of transport have different motivations for using the modes of transport that they choose. Car users think the efficiency of buses is the most important policy measure, whereas motorcyclists put the costs of fuel for travelling as their highest priority. Both car users and motorcyclists think that the policy measures of all buses will improve, but that low chassis buses are the last priority to spend money on, because those users might not be aware that traveling on traditional buses is significantly different to travelling on low chassis buses. Furthermore, the results of the survey implied that it might be difficult to change car users' travel behaviour from using their current modes to using buses, because they strongly rely on traveling by cars. These results are in line with Gatersleben and Uzzell, who pointed out that people tend to prefer a car to other forms of transport for reasons such as flexibility and control, compared to using public transport, which may engender stress and boredom because of delays and waiting times (Gatersleben and Uzzell [17]). 
It should be noted that the number of passenger trips on the Sanyin Line MRT Pilot Bus, the Circle Line MRT Pilot Bus, the Danhei Line MRT Pilot Bus, and the Wanda- Zhonghe-Sulin line MRT Pilot Bus were all significantly increased. Transport planners have around 5-6 years to attract more people to travel by the MRT Pilot Buses before the MRT Tricyclic three-line construction is construction is complete. This evidence suggests that the measure of the MRT Pilot Bus is a significant success in switching private transport users to taking buses.

\section{References}

[1] Cohen, B., Urbanization in developing countries: Current trends, future projections, and key challenges for sustainability. Technology in Society, 28(1-2), pp. 63-80, 2006.

[2] Bloom, D. E., Canning, D., \& Fink, G., Urbanization and the wealth of nations. Science, 319(5864), pp. 772-775, 2008.

[3] Roberts, B., \& Kanaley, T., Urbanization and sustainability in Asia: Case studies of good practice: Asian Development Bank, 2006.

[4] Button, K., Ngoe, N., \& Hine, J., Modelling vehicle ownership and use in low income countries. Journal of Transport Economics and Policy, pp. 5167, 1993.

[5] Steg, L., Car use: lust and must. Instrumental, symbolic and affective motives for car use. Transportation Research Part A: Policy and Practice, 39(2), pp. 147-162, 2005.

[6] Lorna A, G., Effects of human behavior on aggregate carbon intensity of personal transportation: comparison of 10 OECD countries for the period 1970-1993. Energy Economics, 26(1), pp. 1-30, 2004.

[7] IEA. Key World Energy Statistics 2011, Online. http://www.iea.org/publications/free new desc.asp?pubs ID=1199

[8] Fujii, S., \& Gärling, T., Development of script-based travel mode choice after forced change. Transportation Research Part F: Traffic Psychology and Behaviour, 6(2), pp. 117-124, 2003.

[9] Gärling, T., \& Schuitema, G., Travel demand management targeting reduced private car use: Effectiveness, public acceptability and political feasibility. Journal of Social Issues, 63(1), pp. 139-153, 2007.

[10] Richter, J., Friman, M., \& Gärling, T., Soft transport policy measures 2, 2009.

[11] Department of Rapid Transit Systems, N. T. C. G. MRT Tricyclic threeline, Online. http://ntpdrts.ntpc.gov.tw/intro/contact

[12] Bamberg, S., Is a residential relocation a good opportunity to change people's travel behavior? Results from a theory-driven intervention study. Environment and Behavior, 38(6), pp. 820-840, 2006.

[13] Creswell, J. W., Research design : qualitative, quantitative, and mixed methods approaches (3rd ed. ed.). Thousand Oaks, CA ; London: Sage Publications, 2009. 
[14] Feilzer, M. Y., Doing mixed methods research pragmatically: Implications for the rediscovery of pragmatism as a research paradigm. Journal of mixed methods research, 4(1), pp. 6-16, 2010.

[15] Denscombe, M., The good research guide : for small-scale research projects (2nd ed.). Maidenhead: Open University Press, 2003.

[16] Government, N. T. C., Zhonghe District Household Registration Office, Online. http://www.ca.ntpc.gov.tw/hro/zhonghe

[17] Gatersleben, B., \& Uzzell, D., Affective Appraisals of the Daily Commute Comparing Perceptions of Drivers, Cyclists, Walkers, and Users of Public Transport. Environment and Behavior, 39(3), pp. 416-431, 2007. 